President Glenn W. Herrick: I should like to ask what species of aphis were used.

Mr. C. L. Metcalf: The two species used were Aphis spireacola common on Spirea in Maine and Longistigma caryw which is very common here in the lower branches of the sycamore.

President Glenn W. Herrick: I want to ask you how they would compare in resistance with the green apple aphis.

Mr. C. L. Metcalf: The A phis spireacola would be just about the same, Longistigma caryce more resistant than the apple aphis.

President Glenn W. Herrick: The last paper on the program will be given by Mr. W. C. O'Kane.

\title{
ARSENIC ON FRUIT AND FORAGE FOLLOWING SPRAYING
}

By W. C. O'Kane, Durham, N. H.

(Withdrawn for publication elsewhere)

President Glenn W. Herrick: In answering inquiries in regard to orchard spraying I usually state that it is best to keep cattle out of the orchard after spraying until heavy rain has fallen.

Secretary A. F. Burgess: I am particularly interested in these experiments because the question of injuring animals as a result of spraying often comes to our attention. In spraying work throughout the country districts that are infested with the gipsy moth, we adopt the policy of spraying where the owner agrees not to pasture his stock after the spray has been applied. In many cases this is perhaps an unnecessary precaution but it is done simply to prevent controversy or misunderstanding. These experiments, I believe, are the first definite and extensive ones that have been carried through on this particular subject and the information will be of great value to entomologists.

Mr. JAMES Troop: I want to add a bit of experience from Indiana. A number of years ago I carried on some experiments along this line in the orchard at Purdue University. The orchard was in blue grass, and the trees about twenty years old, so that the tops nearly covered the ground. During the spraying season, the superintendent of the farm insisted on letting the sheep run in the orchard. I sprayed this orchard thoroughly for three years with arsenate of lead, using as high as 3 pounds to 50 gallons of water. These trees were sprayed at three different times, each season, and the work was so thoroughly done that the grass under the trees was quite wet. The sheep fed all over this ground, but no harm to the sheep was ever noticed. 
Secretary A. F. Burgess: We use arsenate of lead at a strength which is greater than ordinarily used for orchard spraying, hence there might be more danger in the applications of the spray which we use. Early in the season 10 pounds to 100 gallons of water are used and the amount later is increased to $12 \frac{1}{2}$ pounds and occasionally to 15 pounds if the gipsy moth caterpillars are very large and it is necessary to kill them quickly. Emphasis should be placed on the necessity of keeping the spray mixture thoroughly agitated. We have encountered considerable difficulty in having the arsenate of lead properly mixed with water before it is placed in the tank. Mr. Worthley has just devised a churn which can be used to thoroughly mix the material. This is a matter which should be given attention if thorough spraying is to be done.

Mr. W. C. O'KANE: Regarding arsenic left on fruit after spraying with arsenate of lead, I think I am safe in saying that you never see on apples in the market enough poison to cause the death of anyone.

Adjournment $12.00 \mathrm{~m}$.

\section{Afternoon Session \\ Tuesday, December 28, 1915, $1.30 \mathrm{p} . \mathrm{m}$.}

President Glenn W. Herrick: The first paper on the program will be given by Mr. W. H. Goodwin.

\section{THE CONTROL OF THE GRAPE BERRY WORM (POLYCHROSIS VITEANA CLEM.)}

By W. H. Goodwin, Wooster, Ohio

The grape-berry moth has been known in Ohio through its injuries for nearly fifty years. A number of entomologists have contributed to a knowledge of its life-history and habits: among them are Walsh, Riley, Slingerland, Johnson and Hammar. Several others have been engaged, at various times, in economic measures for berry moth control, but were only partially successful. Experimental work for berry worm control was carried on in 1906 to 1909 by Professor Gossard and assistants, but was finally discontinued on account of the disappearance of the serious infestation of the previous seasons.

Beginning with the seasonal life-history, the winter is passed in the pupal stage. The larva spins a silken cocoon in the fall inside a fold or flap cut out of a grape leaf. These leaves are usually flat on the ground, or they have only one edge buried in the soil, but they are always soft and moist. This seems to be the proper condition of the leaf to make it an attractive place where the larva can spin up for the 